\title{
ORGAN TRANSPLANTATION IN MEDICAL AND LEGAL PERSPECTIVES*
}

\author{
Delford L. Stickeit
}

\section{INTRODUCTION}

The interests of law and medicine interrelate at many points. It is not surprising, therefore, that a number of medical-legal questions have arisen in the wake of recent rapid advances in medical science. Several of these questions have arisen in the field of tissue and organ transplantation. The purpose of this paper is to draw attention to some of these questions; to describe the medical situations out of which they arise; and to suggest, from the medical point of view, the considerations which seem of importance in seeking solutions to the legal problems that exist.

\section{I}

\section{Medical Background}

A. Transplantation: Treatment by Replacement

The main principle upon which transplantation as a form of treatment is based is quite simply the principle of replacement. In situations wherein disease is confined to one part of the body, and that part of the body is damaged beyond repair, restoration of health depends upon some form of replacement of that part. There are three general categories of replacement. First, the replacement may be only a functional replacement, such as, for instance, injections of insulin for the patient with diabetes due to disease of the pancreas, or of thyroid extract for the patient with inadequacy of the thyroid gland. Second, replacement may be in the form of artificial devices: false teeth; artificial limbs; pacemakers of the heart; artificial heart valves; artificial bones; artificial blood vessels; and artificial entire vital organs: artificial kidneys and temporary artificial hearts and lungs. Transplantation of tissues and organs is the third category. The choice of which category of replacement to employ will vary with different tissues and organs depending upon the relative cost and effectiveness of the available types of replacement.

\section{B. Transplantable Tissues and Organs}

Either in animals or in man the following tissues and organs have been removed from the body and transplanted into another individual with a good functional

- Preparation of this paper was supported in part by U.S. Public Health Service Grants GM I2535 and MO I FR 30.

†A.B. 1949, M.D. r953, Duke University. Fellow, American College of Surgeons; Diplomate, American Board of Surgery; Diplomate, Board of Thoracic Surgery. Associate Professor of Surgery, Duke University Medical Center. Chief, Surgical Service, Veterans Administration Hospital (Durham). Contributor of articles to medical and surgical journals. 
result: blood (if blood may be considered a tissue), cornea of the eye, kidney, skin, bone marrow, liver, lung, heart, intestine, pancreas, endocrine glands, ovary, lymph nodes, spleen, bone, cartilage, arteries, and veins. Thus, the list is long, and it includes most of the vital organs. ${ }^{1}$ In the treatment of human disease, success thus far has been confined for the most part to blood, the cornea of the eye, and (to a limited extent) the kidney. Blood vessels, bone, and cartilage may be added to the list, but their function does not depend upon their staying alive in the recipient. From experience with animals, however, there is every reason to believe that all of the other tissues listed eventually will be transplantable in man. Quite a few experimental animals, particularly dogs, are frisking around in good health, living and depending entirely on hearts or livers transplanted from other dogs; ${ }^{2}$ and it would seem now almost to be a rule: if accomplished in dogs it soon will be done in man. Indeed, as this was being written, the press prominently reported the initial success of a homotransplantation of a human heart in South Africa. ${ }^{3}$ Multiorgan transplants also appear imminent, as for example one combination which already has been attempted a time or two in patients with some success: the combination of transplanting kidney and pancreas for the patient with both severe kidney disease and severe diabetes. ${ }^{4}$ It would appear that there will be further advances, and undoubtedly new questions which will be as numerous and as perplexing as those we confront today.

Nerves and any structure the function of which is dependent upon a nerve supply recover only a fraction of normal function when one attempts either transplantation or reimplantation back to the same individual. A measure of success has been achieved with the recovery and reattachment of extremities severed in accidents; but failure of complete restoration of function of the nerves (and therefore persistence of considerable numbness and paralysis of the tranplanted part) results in a rather limited degree of success. ${ }^{5}$ The brain and the spinal cord may for all practical functional purposes be regarded as not transplantable in the foreseeable future.

\section{Kidney Transplantation}

Most of the medical-legal questions to be discussed are of importance with respect to kidney transplantation. Further, since the clinical transplant experience of the author has been entirely with the kidney, kidney transplants will be discussed in the greatest detail. Transplants of cornea, bone, cartilage, and blood vessels raise few if

\footnotetext{
${ }^{1}$ See genetally M. Woodroff, The Transplantation of Tissues and Organs 25I-6I5 (1960); Shumway, Angell \& Wuerllein, Process in Transplantation of the Heart, 5 Transplantatron 900 (1967); Starzl et al., Homotransplantation of the Liver, 5 Transplantation 790 (1967).

${ }^{2}$ See Shumway, Angell \& Wuerflein, supra note 1, at 9ox-02; Starzl et al., supra note 1.

${ }^{8}$ See, e.g., N.Y. Times, Dec. 4, 1967, at $x$, col. 2; $i d$. at 57, col. I.

'Kelly et al., Allotransplantation of the Pancreas and Duodenum Along With the Kidney in Diabetic Nephropathy, 6I SURGERY 827 (1967).

See generally Inoue et al., Factors Necessary for Stuccessful Replantation of Upper Extremities, I65 ANNALS OF SuRg. $225(1967)$.
} 
any additional medical-legal questions. Transplantation of liver, lungs, heart, skin, gonads, endocrine glands, and other tissues no doubt will create new medicallegal questions; but clinical experience with these thus far has been scant.

\section{Kidney Transplantation and the Artificial Kidney}

For the patient who has lost all kidney function of his own, these forms of treatment provide means-the only two means available at present-to maintain life. Both the artificial kidney and transplantation have shortcomings, and both fall short of being ideal forms of treatment; but with either, health can be restored to the point of return to gainful employment. The advantages and disadvantages of each of these forms of treatment are such that they complement each other; and in the course of treating a particular patient, treatment is likely to depend primarily upon the artificial kidney at times and primarily upon a transplant at other times. In most centers, therefore, these two forms of treatment are available in a combined program. Both are complex. Both require great financial outlays and place a heavy demand upon skilled and professional services which are in short supply. By using both forms of treatment in a combined program more patients can be treated than if all available resources were concentrated on one or the other.

\section{Judging the Success of Kidney Transplants}

Well over a thousand kidney transplants have been performed in patients throughout the world. ${ }^{6}$ This experience has been almost entirely during the last thirteen years, and three-quarters of it has been in the last five years or so. In judging success or failure in an individual patient or in a series of patients, it is important to remember that kidney transplants can function well for a number of weeks or even months only to fail later on. The transplant can fail after the patient has returned home from the hospital and made what would appear to be a complete recovery. Most of such failures, however, occur during the first six months; the failure rate decreases thereafter. The one-year point in time is arbitrarily taken as a point at which to judge success or failure, partly because one year is a round number but more significantly because transplants that are functioning well at this time will function well for a number of additional years with but few exceptions. Because such a large proportion of our total experience has been in the last five years, it is not yet possible to predict the long-term success rate, that is, results as of five, ten, or more years after the transplant.

Results are steadily improving. The improvement appears to be partly the improvement that accompanies experience and partly improvement from new techniques of management. Particularly encouraging is the progress already made and in prospect with regard to avoiding or overcoming the problem of immunologic rejection of incompatible transplants. This problem, however, is still the main

\footnotetext{
${ }^{6}$ Murray, Barnes \& Atkinson, Fifth Report of the Human Kidney Transplant Registry, 5 TransplantaTION 752 ( 1967 ).
} 
barrier which stands in the way of transplantation on a much larger scale and with a much greater success rate than is now possible. ${ }^{7}$

Failure of the transplant sometimes but not always results in death of the patient. The transplant that has failed can be removed; and in many cases treatment with the artificial kidney can be used until another donor is available.

\section{Living, Related Kidney Donors}

Kidney transplants can be divided into two main categories which can be considered separately: one in which the kidney is removed from a healthy close blood relative of the recipient, that is, a parent or a brother or sister; and the other in which the kidney is removed from the body of an unrelated person who has just died, the so-called "cadaveric" transplant.

With the use of living donors who are parents, brothers, or sisters of the recipient the success rate as of one year post-transplant is about sixty-five to seventy per cent. ${ }^{8}$ In the successful cases health is restored either completely or almost completely with return to work in most instances. Because of the long-range uncertainties already discussed, transplant patients are not encouraged to have children; nevertheless, a small number of women have had children and have experienced little or no trouble in the process.

A most important aspect of the use of a living donor is the risk to the healthy person who undergoes removal of one of his two normal kidneys. The risk can be described in two components: one, the immediate risk of operation; and the other, the long-range risk of living with one healthy kidney rather than with two. Both of these risks are small and hard to assess precisely; however, the following statements can be made. In the worldwide experience with over $65^{\circ}$ such operations there have been no known fatalities or permanent disabilities. ${ }^{10}$ The immediate risk of such ill effects therefore is low, but it is doubtful that the figure will remain zero forever. The risk of general anesthesia alone is about one in 2,000, and if one adds a comparable factor for the operative procedure itself one gets an over-all immediate risk of about one in $I, 000$ or some fraction of one per cent.

With regard to the long-range risk of living with one healthy kidney rather than with two, the first point to understand is that one healthy kidney provides more than adequate function. In other words, one's health is entirely normal so long as the one kidney is healthy. The risk lies entirely with the small probability that, through disease or injury, the person might lose the remaining kidney and need the "spare" and not have it. The probability that such a situation might arise is

\footnotetext{
${ }^{\top}$ See generally id.

${ }^{8} I d$. at 774.

'See Hume et al., Comparative Results of Cadaver and Related Donor Renal Homografis in Man, and Immunologic Implications of the Ontcome of Second and Paired Transplants, 164 Annals or Sung. 352, $386-87$ ( 1966 ).

${ }^{10}$ Murray, Barnes \& Atkinson, supra note 6, at 756, table 3 .
} 
quite low-so low that insurance companies insure at standard rates if the patient has had a kidney removed and is healthy in all other respects. ${ }^{11}$

Although both the immediate risk and the long-range risk of undergoing removal of a kidney are small, these risks are not negligible. Although not great, these risks are significant, and they are risks to which a healthy person would not submit lightly.

In the experience with the use of living, related donors it is perfectly clear that the benefits gained by the recipients have exceeded by far the losses, in terms of pain and temporary disability, suffered by the donors. In this sense the experience has been very good and gratifying. Legal and moral questions are raised, however; and of course the reason is that the donors in themselves stand to gain nothing tangible for the risks which they take.

\section{Cadaveric, Unrelated Kidney Donors}

As already noted, in this transplant situation the kidney used is one which has been removed from the body of a person just after death. The first consideration in this situation is the obvious fact that there is no risk to a healthy donor.

The second consideration is that patients who receive a cadaveric transplant usually wait many weeks or months before a suitable kidney becomes available. All this time the patient must be maintained on an artificial kidney, and treatment by artificial kidney is expensive and scarce. The number of cadaveric kidney transplants that can be performed therefore is limited partly by limited availability of artificial kidneys. In contrast, recipients of kidneys of living, related donors do not go through a long waiting period, require far fewer treatments on the artificial kidney, and therefore contribute relatively little to the shortage of the artificial kidney.

The third consideration is that kidneys that are to be transplanted ought to be removed not later than thirty minutes after the death of the donor and preferably sooner. If the kidneys are not removed within this time, post-mortem deterioration is excessive, and they cannot be used. ${ }^{\mathbf{1 2}}$

The fourth consideration is that the success rate as of one year post-transplant is approximately thirty to forty per cent. ${ }^{13}$ The results therefore are only slightly more than half as good as with the use of living, related donors. The difference in success between using a living, related donor and using a cadaveric, unrelated donor is due to the difference in relationship between donor and recipient and not due to the fact that the donor is living in one situation and dead in the other. In other words, the results are about the same with living unrelated donors as with cadaveric unrelated donors. ${ }^{14}$

\footnotetext{
${ }^{11}$ See Merrill, Clinical Experience is Tempered by Genuine Human Concern, I89 J.A.M.A. 626, 627 (1964).

${ }^{12}$ See Couch, Curran \& Moore, The Use of Cadaver Tissues in Transplantation, 27I NEw ENG. J. MED. $69 \mathrm{r}(1964)$.

${ }^{13}$ Murray, Barnes \& Atkinson, supra note 6, at 774 .

14 See id. at $77 \mathrm{r}$.
} 


\section{Other Donors}

Healthy, living, unrelated donors constitute a minor category for reasons which already have been stated. Their use entails risk to a healthy person; and the anticipated success rate is as low as with the use of unrelated cadaveric donors. Nevertheless, a small number of such donors have been used, mostly spouses of recipients and prisoner volunteers.

In a biologically similar category is the use of a kidney removed from another patient as a surgical specimen. "Surgical specimen" is the term applied to the tissue or to an organ removed from a patient during a surgical operation. Such tissues and organs usually are diseased, deformed, or functionless prior to removal and therefore are rarely suitable for use as transplants. On occasion, however,-for instance, in an operation performed for the treatment of hydrocephalus, or in an operation for disease low in the ureter (the tube that transmits urine from kidney to bladder)-the necessary surgical procedure entails removal of a healthy kidney. With the use of such an organ as a transplant there is the advantage of being able to plan the procedure, as with other living donors. The anticipated success rate, however, is as low as with the use of cadaveric donors because donor and recipient are unrelated.

Rarely, the patient with kidney disease will have a healthy identical twin who is a suitable donor. Such a donor is uniquely suitable because the biologic problems of rejection are avoided. Tissues may be transplanted from an identical twin with anticipation of the same degree of acceptance as if the transplant were from one part of the body to another in the same individual. ${ }^{15}$

A small number of kidney transplants have been performed from chimpanzees and from baboons to man. There was no success with the use of baboons, which phylogenetically are not as closely related to man as are chimpanzees. The survival of one patient on a chimpanzee kidney for nine and one-half months ${ }^{16}$ is a highly significant fact which alone justifies consideration of further use of chimpanzees for this purpose, especially if improved means of testing for tissue compatibility are developed or if methods to prevent rejection are developed which are much better than the methods presently available.

\section{II \\ Medical-Legal Questions}

\section{A. The Legality of Donation of Human Tissues}

\section{Healthy Adult Donors}

In the worldwide experience with over 650 healthy adults who have donated a kidney remarkably few questions have arisen with regard to the legality of the

\footnotetext{
${ }^{15}$ See Murray \& Harrison, Surgical Management of Fifty Patients with Kidney Transplants Including Eighteen Pairs of Identical Twins, I05 AM. J. Surg. 205, 2r4 (1963).

${ }^{16}$ Reemtsma et al., Renal Heterotransplantation in Man, r60 AnNars of Surg. $384,392-94$ (1964).
} 
donations, except for questions which pertain to informed consent of the donor. From the medical standpoint, therefore, there appears to be little need for laws to legalize such donation formally. The shifting emphasis from living to cadaveric donation may decrease still further the importance of considering enactment of such laws.

The law in Italy is an interesting exception. A law was enacted in I940 which specifically forbade the removal of a part or an organ of the human body the loss of which permanently diminishes physical integrity. ${ }^{17}$ Significantly, in the wake of advances in the field of kidney transplantation, a new law has been enacted which changes the 1940 statute at least with respect to kidney transplantation. ${ }^{18}$ This law permits kidney transplantation from living donors who haye given their consent, and establishes elaborate administrative mechanisms to control practice in this field. It is significant to note that judicial approval must be obtained before the removal and transplantation will be allowed.

Consent of the donor must be entirely voluntary, and the donor must be informed as to what the procedure entails. These qualities of consent have been discussed at great length as they pertain to this and to other consent situations; all this need not be reviewed in detail here. ${ }^{19}$ One point, however, does deserve emphasis. The donor does not stand to derive physical benefit from the procedure to which he submits; therefore, the critical attention that has been given to the quality of the consent of the healthy living kidney donor is appropriate. Both with regard to donors who are closely related to the recipient, and with regard to unrelated healthy volunteers, prisoners, and others, the question frequently is raised whether the consent is properly informed and voluntary. Most difficult to deal with is the question whether subtle forms of coercion enter into family and other situations sufficiently to invalidate consent. Opinions vary on these questions of consent; and opinions vary with regard to the essential morality or immorality of the use of healthy, living donors. Accordingly, practice varies from, on the one hand, preponderant use of healthy, living donors $^{20}$ to, on the other hand, exclusion of healthy, living donors from consideration. $^{21}$

The use of prisoner volunteers as kidney donors deserves a special note. Although no grounds have been established on which to declare the use of prisoners as absolutely wrong legally or morally, in Denver this practice was discontinued despite considerable experience which demonstrated unique medical and scientific advantages in their use. The reason given for the discontinuance of this practice was that the

\footnotetext{
${ }^{27}$ Cortesini, Outlines of a Legislation on Transplantation, in Ethics in MEdical Progress I7I, I72 (G. Wolstenholme \& M. O'Connor eds. rg66).

is Presidential Decree of June 26, 1967, [1967] Gaz. Uff. 3478.

${ }^{20}$ See I. Ladinger \& R. Newhan, Clinical Investigation in Medicine (1963).

${ }^{20}$ See Starzl et al., Chronic Survival After Human Renal Transplantation, I62 Annals of Surg. 749 (x965).

${ }^{31}$ See Dossetor et al., Cadaver Kidney Transplants, 5 Transplantation 844 (1967).
} 
use of prisoners, however properly handled in the local situation, was deemed inevitably to lead to abuse if accepted as a reasonable precedent and applied broadly. ${ }^{22}$

\section{Healthy Donors who are Minors}

Because the validity of their consent is subject to question, persons under twentyone years of age generally are not considered as kidney donors. The issue is forced, however, in identical twin cases because the healthy identical twin is, biologically, uniquely suited to donate. In a discussion of several judicial cases, ${ }^{23}$ one involving a set of identical twins nineteen years of age and two involving sets who were fourteen years of age, Curran observes that the action of the court in approving the renal transplant operation in each case was based (I) partly on the consideration that the donors understood the procedure and wished to donate and (2) partly on the consideration that, if approval had been denied, the donors would have suffered emotional trauma in being denied the opportunity to save their twins. While the actions of the courts in these cases may leave intact the principle that consent given solely by parent, guardian, or court on behalf of a minor is not valid except for procedures which benefit the minor, these cases do not constitute precedent for the general use of donors who are minors, even when the donor is an identical twin. ${ }^{24}$

\section{Surgical Specimens as Transplants}

As mentioned above, the opportunity for use of surgical specimens as transplants arises infrequently. Nevertheless, this situation raises two interesting medical-legal considerations. (I) If there is more than one method of treatment available for the patient who is the donor, the choice of treatment must not be influenced by the need to use the surgical specimen as a transplant to treat another patient; and the operation to remove the organ must not be modified at the risk of the donor to benefit the recipient, except by consent of the donor. (2) Such use of a surgical specimen may be regarded as extraordinary; it therefore might be wise to obtain the consent of the donor for such use of a specimen, even if disposition of the specimen is normally not the legal prerogative of the patient. Informing the patient generally

\footnotetext{
${ }^{22}$ Remarks of T. Starzl, in Ethics in Medical Progress 75-77 (G. Wolstenholme \& M. O'Connor eds. 1966).

${ }^{23}$ Curran, A Problem of Consent: Kidney Transplantation in Minors, 34 N.Y.U.L. Rev. 891 (1959), reprinted in I. Ladimer \& R. Newman, stipra note r9, at 237. This article discusses Masden v. Harrison, No. $6865 \mathrm{I}$ Eq. (Mass. Sup. Jud. Ct., June 12, 1957); Husky v. Harrison, No. 68666 Eq. (Mass. Sup. Jud. Ct., Aug. 3o, 1957); Foster v. Harrison, No. 68674 Eq. (Mass. Sup. Jud. Ct., Nov. 20, 1957).

${ }^{24}$ See Curran, supra note 23, at 893. In Bonner v. Moran, 126 F.2d 121 (D.C. Cir. 194I), the court was confronted with an analogous problem. A fifteen-year old boy consented to removal of his skin, in a graft operation, for the benefit of his cousin. He was taken to the operating physician by an aunt and there gave his consent, but his mother was never told of the operation. The physician was held liable, the court reasoning that "here we have a case of a surgical operation not for the benefit of the person operated on but for another, and also so involved in its technique as to require a mature mind to understand precisely what the donor was offering to give. ... [T] [Te court below should, in the circumstances we have outlined, have instructed that the consent of the parent was necessary." Id. at 123. Implicit in this reasoning is the conclusion that, if consent had also been obtained from the parent, the court would have sanctioned the skin graft operation performed upon one minor for the bencfit of another.
} 
is advantageous, and there is the additional consideration that members of certain religious sects might oppose such use of a specimen on the same grounds that they oppose donation of blood for transfusion.

\section{Post-mortem Donation of Human Tissues}

With this topic it must be noted first of all that tissue and organ transplants are but one of several medical uses which are made of human bodies or parts thereof post-mortem. Whole bodies are dissected for teaching and research in human anatomy. Autopsies are performed to determine the cause of death either for medical purposes only or at the direction of the coroner or medical examiner in the public interest; and autopsies are useful in many aspects of medical research. Growth hormone extracted from human pituitary glands is an important therapeutic agent; and in some countries, particularly Russia, blood obtained freshly post-mortem has been an important source of blood for transfusions. Transplantation of the cornea of the eye is an established surgical practice which is completely dependent upon postmortem donations. An increasing proportion of kidney transplants are procured from post-mortem sources. Limited use has been made of transplants of liver, Iung, skin, heart valves, and other tissues obtained from dead bodies, and there is every reason to believe that progress in the field of transplantation will greatly increase the need for such transplants in the foreseeable future. In summary, human bodies and parts thereof are needed and used extensively in all three of the major subdivisions of medical science: diagnosis and treatment, education, and research.

Numerous legal considerations are encountered in fulfilling the needs listed in the preceding paragraph. Medical and legal technicalities intermesh so extensively on this subject that it is possible only through appropriate statutes to provide adequately for these medical needs and to provide at the same time due regard for the various rights and interests involved (some of which conflict with each other). Sound statutes require considerable joint medical and legal effort in the drafting and then considerable political effort and perhaps compromise to secure passage. A lag between the time a need is identified and the time it is provided for in statutory law is understandable, therefore, but disadvantageous nevertheless.

A special committee of the National Conference of Commissioners on Uniform State Laws is now, after a number of years of extensive medical and legal research, about ready to recommend a Uniform Anatomical Gift Act, which would provide for those uses of human tissues which are not provided for in autopsy laws. ${ }^{25}$ Because not only the Uniform Anatomical Gift Act but also a summary of the underlying medical and legal considerations will be available shortly from the National Conference, there is no reason here to develop this topic in detail. To emphasize the scope and magnitude of this project, however, it is noteworthy that the proposed uniform act will take all of the following considerations into account:

\footnotetext{
${ }^{25}$ See Stason, The Role of Law in Medical Progress, in this symposium, pp. 563, 57r-72.
} 
(I) all of the medical uses of human tissues listed above, including the problem of securing organs within minutes of death for use as transplants; (2) the interests of the deceased in his own body; (3) the interests of the surviving spouse, relatives, or person assuming the duty of burial; (4) the public interest-for instance, in finding the cause of death when suspicious circumstances are involved and in medical education and research; (5) property rights in dead bodies; (6) existing autopsy laws; (7) the use of unclaimed bodies for medical education; (8) liability for mutilation of human bodies; (9) consent for the utilization of human tissues, either post-mortem by relatives or by will or other form of consent by the deceased; (Io) determination immediately at the time of death that this consent is legally valid; and (Ir) conflict of laws between states. Although most states already have statutes that deal with some of the above considerations, in no state are the existing laws adequate to cope with all the problems raised. The Uniform Anatomical Gift Act will soon be available as a possible solution to these inadequacies. It is hoped that it will be promptly considered and enacted by the fifty state legislatures.

Opportunities for completing successful transplant operations would be increased at present by facilitating the transportation of human tissues and organs across state lines. The need for this transportation will become more acute in the future. Such transportation probably will involve federal as well as state laws. Interrelations between blood banks, the licensing of blood banks, and federal regulations regarding interstate shipments of blood apply to the transfusion of blood when it must be transported across state lines. As tissue and organ banks are developed and used more and more it will be necessary to coordinate medical and legal developments in considerable detail in order to arrive at workable arrangements for the transportation of parts of the human body.

\section{B. Definition of the Time of Death}

For reasons that will be given, it is not justified at present to deviate from the traditional medical and legal definition of time of death, which is that point in time when first it can be declared that heart, lungs, and brain all have irrevocably ceased to function. It generally is not difficult to identify this point in time with accuracy, and certainly death has occurred by this time; plausible arguments might be made for an earlier but probably not for a later time.

Until recently use of this definition had raised no serious questions. Now, however, questions regarding the management of patients during their last illness and definition of time of death are topics which are under considerable discussion. ${ }^{2 B}$ Although the discussion has not arisen particularly with respect to transplantation, the subject is of obvious importance to transplantation because of the increased use that is being made of cadaveric donors. Patients now are resuscitated who

\footnotetext{
${ }^{20}$ See, e.g., Ethics in Medical Progress passim (G. Wolstenholme \& M. O'Connor eds. 1966); Williamson, Life or Death, Whose Decision?, I97 J.A.M.A. 793 (1966).
} 
formerly might have been pronounced dead. Situations have been created wherein patients are kept alive by rather artificial means-so artificial, sometimes, that important questions are raised seriously. Is treatment being carried too far? Is the treatment really accomplishing any good? Should we re-examine the traditional medical and legal definition of time of death?

When the dying patient in question happens to be a prospective donor for another patient awaiting a transplant, another consideration is added which constitues further reason to question, critically, practices which pertain to timing the pronouncement of death. In transplanting tissue from a cadaveric donor there is the need to remove the tissue from the body after the death of the donor but before the death of the tissue being removed. Tissues such as skin and the cornea of the eye remain viable up to twenty-four hours after death of the donor, and twenty-four hours is ample time to secure such tissues for use as transplants. As already mentioned, however, the time factor is more critical with tissues such as kidney, liver, lung, heart, and others which deteriorate rapidly after the death of the donor and which must be removed within a half hour or less of the time of death. If not removed within this critically short period of time, deterioration of the tissue is excessive, and the transplant does not function satisfactorily.

It of course would be medically, legally, and ethically wrong to do anything at the expense of the life or the comfort of the dying patient who is a prospective donor, just to secure a healthy transplant. On the other hand, it would seem one also has the obligation not to delay pronouncement of death unnecessarily when such a delay would reduce the likelihood of successful treatment of the recipient. The needs of the recipient constitute a new factor to be weighed in the situation which surrounds the death of a donor. No longer is an unnecessary delay inconsequential. Such a delay now could conceivably make the difference of life and death to the prospective recipient who awaits transplantation, but the possibility of this occurring or of a transplant's being rendered impossible by an unnecessary delay in fixing the time of death is quite remote.

The suggestion has been made that time of death be defined in new terms. Couch $^{27}$ has suggested that pronouncement of death not be delayed until all the vital organs cease to function but that death be pronounced as soon as it is certain that the function of any one irreplaceable vital organ has ceased irrevocably. By definition any biologic organism depends for its existence upon all its vital organs; and when the organism loses any one of its vital organs it no longer exists as a whole organism but only as a disintegrated collection of organs. After one vital organ is lost, signs of life in the other organs will persist for a time and, if artificially supported, for quite some time, varying considerably with the particular organ

\footnotetext{
${ }^{27}$ Couch, The Legal Aspects of Human Organ Transplantation, in Proceedings of First INTERNAtional Congress [1967] of the Transplantation Society (forthcoming).
} 
in question; but such life is quite different and distinguishable from the life of the integrated organism.

These considerations can be applied to any biologic organism, especially to man. In man the question arises particularly in situations of irreversible loss of function of the brain and central nervous system. Indeed, certain practices already have been established which essentially regard human life as ceasing at that point in time when there is irreversible and complete loss of function of the brain. With regard to the decision whether or not to resuscitate or to restart a heart which has stopped, it now is generally accepted practice to base the decision not upon the likelihood of restoring function of the heart but upon the likelihood of restoring function of the brain. Restarting the heart is not attempted if function of the brain has been lost irrevocably. ${ }^{28}$

One must hasten to add there are many strictly medical questions to be answered before we can seriously consider defining time of death in terms of the central nervous system alone rather than in the traditional terms of cessation of all vital functions. How does one define, for instance, when loss of function of the brain is irreversible? The electroencephalogram (EEG) has been suggested as a useful tool with respect to this question, but a precise definition of time of death of the brain based on the EEG has not been established. How long must the EEG waves be absent before death is certain? And how much does this time vary with differing causes of death? For instance, will the time be the same for barbiturate poisoning as for brain tumor or for physical trauma to the brain? ${ }^{20}$

Arriving at a medical consensus on questions such as these and public acceptance of death defined in new terms undoubtedly will take some time. In the meantime, there seems to be no compelling necessity and no other justification (including a better alternative) for deviating from the traditional medical and legal definition of time of death.

\section{Shortcomings of Available Insurance}

\section{Professional Liability Insurance and Clinical Investigation}

Transplantation of tissues and organs engages physicians and surgeons with clinical investigation of two types. First, as a form of treatment of patients who are recipients, transplantation is still in the investigational phase in a number of respects. Second, healthy human volunteers are used as subjects in experiments, for instance, in test skin graft experiments, which are playing an important role in elucidating some of the biologic problems of transplantation in man.

Bergen $^{30}$ points out that most professional liability insurance policies are not explicit with regard to coverage of clinical investigation and therefore that interpre-

\footnotetext{
${ }^{28}$ See Jude, Kouwenhoven \& Knickerbocker, A New Approach to Cardiac Restuscitation, I54 ANwats OF SURG. 3II, 3I6-I7 (Ig6I).

${ }^{20}$ Ethics in Medicat Progress 69 (G. Wolstenholme \& M. O’Connor eds. 1966).

${ }^{80}$ See Bergen, Instrance Coverage for Clinical Investigation, J.A.M.A., Aug. 7, 1967, at 305.
} 
tation is subject to question. He states that there is no record of a court deciding whether the language of a professional liability policy covered liability associated with clinical investigation. He cites cases, however, wherein other questions of extent of coverage were raised. From such cases he observes that when insurance policies are tested in court the ruling tends to be in favor of the insured if the language is not clear. He suggests that only for activities which clearly are outside of the physician's professional practice would the courts be likely to deny coverage. In other words, most medical professional liability insurance policies probably cover clinical investigation though not explicitly and not beyond some question. ${ }^{31}$

Bergen then raises a question that is of interest with respect not only to professional liability insurance but also with respect to insurance coverage for experimental subjects and healthy living kidney donors, which is discussed in the following paragraphs. The question is, who should pay for the coverage? He suggests that the cost of underwriting any additional protection for the clinical investigator should be the responsibility of the organization which financially sponsors the research. The reasons he gives are (I) that the cost of such insurance is appropriately a part of the operational cost of the sponsoring organization, like any other cost; (2) that sponsoring organizations need protection themselves and could well provide personal insurance protection for the clinical investigators who work under their sponsorship; and (3) that the sponsoring organization could probably obtain the insurance coverage at lower cost than the combined cost of separate coverage for each of the investigators.

\section{Insurance for Healthy Volunteer Subjects of Human Experiments}

Insurance for healthy subjects of human experimentation generally is not available. Such insurance is needed to cover the financial risks to which subjects submit and for which there is no insurance coverage unless the physician in charge is found guilty of malpractice; insurance of this type, if widely used, would accomplish the same result as would the judicial evolution of a legal principle of "liability without fault" for harm resulting from experimentation. ${ }^{32}$ The underwriting of such risks

\footnotetext{
${ }^{31}$ See id.

${ }^{\text {as }}$ Such strict liability might be accomplished by carrying out the implications of the widely stated but unfortunate principle that "the physician experiments at his peril." See notes $4 \mathrm{I}-42$ infra and accompanying text. But, while the object of shifting the burden of losses suffered by research subjects to those supporting the research is a valid one (see generally Comment, Legal Implications of Psychological Research with Human Subjects, I96o Duxe L.J. 265, 274), the medical profession would have good reason to resent the achieving of this result by a process imputing blame to the experimenters in every case. Insurance of a nonmalpractice variety would seem to be the more desirable way of providing the needed protection for research subjects. Perhaps a legal doctrine imposing liability on the experimenter for failure to provide such insurance, enabling the injured subject to recover even in the absence of other negligence, would ultimately be appropriate; however, the availability and widespread use of such insurance would be prerequisites to such a legal rule, unless a duty to provide such insurance were created by legislation or regulatory action. In addition, the premiums on such insurance, which would presumably be set by negotiation between the insurer and the experimenter, would provide useful checks on overly dangerous research.
} 
would accomplish two things: (x) It would relieve the subject of the financial risk associated with unanticipated but possibly serious untoward effects of the drug or procedure to which he submits. Admittedly, subjects in clinical investigation incur such expenses only rarely as a result of their participation; but when such expenses are incurred, it would seem that the subject ought not to be the one to pay. (2) In the event of such an unfortunate occurrence, insurance coverage of this nature would eliminate the motive of the subject to sue the physician for malpractice or to sue the hospital or the granting agency for negligence in order to recover his losses (in much the same way that workmen's compensation insurance protects employers from suits for negligence in connection with injury sustained by employees on the job). In short, such coverage would protect the subject, the physician, the institution, and the supporting agency. For the same reasons which Bergen expresses clearly with respect to professional liability insurance, ${ }^{33}$ the supporting agency would appear to be in the best position to provide such coverage. In most instances this would be the National Institutes of Health.

\section{Insurance for Healthy Living Kidney Donors}

The kidney donor probably ought not to be forced to pay the expenses of his donation, whether the anticipated ordinary expenses of absence from work, travel, and medical care before and after the operation or the rare but possibly heavy expenses of treatment and disability resulting from unexpected complications. In practice, relatives, employers, and research grants usually assume the responsibility for the anticipated expenses, but there is no alternative but for the donor himself to take the risk of large unanticipated expenses. In this regard his position is quite comparable to the healthy volunteer in a human experiment. So long as kidney transplantation is carried out under the sponsorship of research grants, perhaps such insurance coverage could most appropriately be covered as suggested in the preceding section on healthy volunteer subjects. If the use of healthy living donors still is commonplace after kidney transplantation is established as a routine form of treatment, perhaps the recipient's health insurance carrier would be the one in the most appropriate position to underwrite this risk.

\section{Gaps in Health Insurance Coverage for Research Patients}

For a number of reasons patients who are the subjects of clinical investigation not infrequently have difficulty maintaining their health insurance in effect; and the organization which is sponsoring the research naturally limits its responsibility to paying only for treatment which is essential to the research. The resulting gaps can present problems to the patient, to the physician, and to the sponsoring organization; but these problems may dissipate as the trend to broader and broader coverage of the costs of health care continues.

${ }^{83}$ Bergen, supra note 30 , at 306. 


\section{Self-Government Within the Medical Profession}

Stason ${ }^{34}$ has observed that professional codes constitute an important aspect of law. To what extent ought the legal questions raised by tissue and organ transplantation to be answered in the written and unwritten codes and standards of the medical profession?

A principle which has been established with respect to transplantation of cadaveric kidneys provides a good example of the resolution of a quasi-legal question within the medical profession. The principle is that there shall be a complete separation of authority and responsibility between the physician or group of physicians who are responsible for the care of the recipient and the physician or group of physicians who are responsible for the care of the patient who is a prospective donor. In other words, no one on the transplant team has any authority in the care of the donor before his death, and the determination of the time of death is exclusively the responsibility of the physician in charge of the patient who is the prospective donor. ${ }^{35}$ The possibility of a physician's becoming involved in a potential conflict of interest between donor and recipient is thus recognized. Because of the pressures of time and the need to remove kidneys within a half hour of the time of death, and because the initial steps in preparing the recipient for the transplantation are undertaken before the death of the donor, this question can legitimately be raised: Will the care of the dying prospective donor tend to be any different because he is a prospective donor? In other words, can concern for the prospective recipient influence the care of the prospective donor? And, if so, is there any possibility that this will not be in the best interests of the prospective donor? Such a possibility, even though improbable, would be better excluded altogether; and to this end the principle noted above has been formulated and generally adopted in those transplant centers where cadaveric donors are used. This principle is included in the Uniform Anatomical Gift Act, and it probably is wise to give this principle the additional force of being incorporated into statutory law; but the significant point in the present context is that the principle initially was recognized and was adopted within the medical profession, as it should have been, and was not first imposed by external law.

Because of the investigative aspects of tissue and organ transplantation, the clinical practice of transplantation is subject to the codes of ethics for conducting clinical research, particularly the Nuremberg Code, ${ }^{36}$ the Declaration of Helsinki, ${ }^{37}$ and the statement of the Medical Research Council of Great Britain. ${ }^{38}$ These professional

\footnotetext{
${ }^{36}$ Address by E. Blythe Stason at Lawyers and Physicians Conference, Lake Junaluska, N.C., Aug. I2, 1967.

${ }^{\mathrm{II}}$ See Couch, Curran \& Moore, supra note 12, at 693-94.

${ }^{30}$ Trials of War Criminals Before the Nuremberg Military Tribunals Under Control Council Law No. 10, 2 The Medical Case I8I (1947), reprinted in Beecher, Experimentation in Man, I69 J.A.M.A. 46I, 472-74 (1959).

${ }^{37}$ World Medical Association, Code of Ethics of the World Medical Association [Declaration of Helsinki], in 2 BRIT. MED. J. I77 (I964) (accepted at Helsinki in June $x_{964}$ ).

${ }^{38}$ Medical Research Council, Responsibility in Investigations on Human Subjects, 2 BRrr. MED. J. I78 (1964) (statement in Annual Report for $1962-63$ ).
} 
codes, judging from the extent to which they have been followed, appear to be good examples of effective self-government. In a legal analysis of the status of clinical investigation, Ladimer ${ }^{39}$ observes that clinical investigation has been practiced extensively with remarkably little control by external law.

Some medical-legal questions, of course, practically insoluble except in the courts or by statutory law. Examples include questions discussed in two preceding sections: the questions pertaining to the identical twin donors who were minors and the questions that prompted the drafting of the Uniform Anatomical Gift Act.

Although professional codes may not be regarded generally as law, and although for the most part they are unwritten, they have some of the important attributes of law. Within the professional group to which they apply they constitute rules, principles, and standards of practice and conduct which generally are followed within the group, and violations are subject at least to the penalty of sacrifice of standing or reputation within the group and possibly to greater penalties. The greater penalties, rarely imposed, would include formal censure by, or suspension from membership in, the county medical society; suspension of hospital privileges (the privilege to treat patients in the hospital); and revocation of the doctor's license to practice. Professional codes of course apply only to a small segment of society; and compared to laws of local, state, and federal governments, professional codes generally are less formal and systematized in their creation, modification, and enforcement. The great advantages of simplicity and directness are strong arguments for self-government. There would appear, however, to be the proviso that self-government is satisfactory only insofar as it is effective and insofar as it is consonant, both in content and enforcement, with the expectations of society generally.

Self-government seems to relate to general law in two important respects. First, as already implied, enlightened self-government from within the profession obviates the need for government from without. Second, when a practitioner is called to task in a lawsuit he may be held liable if it be established that he failed to measure up to the standards and codes of practice within his professional community.

E. Transplantation, Clinical Investigation, and Medical Practice

Discussion in preceding sections has shown that legal problems raised in the area of transplantation are similar to legal problems in clinical investigation. One further point that is illustrated in experience with transplantation is that the investigative and the established components of medical practice may not be separable. A question that is often asked is whether kidney transplantation is of established value as a form of treatment or whether it is still an investigative form of treatment. The answer is that it is not one or the other but both. Kidney transplants

${ }^{80}$ See Ladimer, Ethical and Legal Aspects of Medical Research on Human Beings, 3 J. PuB. L. 467, 47I, 497 (I954), reprinted in I. LADIMER \& R. NewMaN, stipra note I9, at I79. 
provide effective treatment which is obvious even to the untrained observer, but at the same time major unsolved problems limit the effectiveness of the treatment. There is no justification for undertaking this form of treatment without simultaneously conducting studies aimed at improving the treatment.

The investigative component of medical practice, characterized by the acquisition of new knowledge, coexists in practice with the established component, characterized by the utilization of existing knowledge. In a legal analysis of clinical investigation in relation to medical practice, Ladimer ${ }^{40}$ emphasizes with a number of points the closeness of the relationship between the investigative and the established components: (I) Both the profession and society generally regard the advancement of scientific medical knowledge as one of the duties of the profession. (2) Between two extremes is a spectrum of types of practice which can be regarded as investigational in varying degrees. On the one hand there are highly formal and controlled clinical studies with either patients or healthy human volunteers. On the other hand there are trial and error searches among several established forms of treatment for the thing which works best in a given patient, which may or may not result in addition to general knowledge and which therefore may or may not be regarded as research. (3) With few exceptions all physicians engage at one time or another in practices which in some degree are investigational.

Considering that clinical investigation and established medical practice are so closely intertwined, it is remarkable that there has been so little formal recognition of the legitimacy of clinical investigation. As already noted, this may reflect a healthy degree of self-government within the profession. One is troubled, however, by the negativism of the legal maxim to which reference is usually made whenever the legality of clinical research is discussed-"the physician experiments at his peril."41 It is reassuring to note that historically this admonition arose out of cases of irresponsible experimentation with new treatments without making full use of established forms of treatment. ${ }^{42}$ Nevertheless, one is left with the feeling that laws that

\footnotetext{
${ }^{10}$ Ladimer, stupra note 39 , at $469-70,482-83$.

41 "In ${ }^{2} 767$ the first malpractice case involving alleged experimentation, Slater v. Baker, 95 Eng. Rep. 860 (K.B. 1767), established the rule that experimentation was at the physician's peril." Id. at 476. One authority has emphasized the negativism implicit in the law's characterization of any surgical procedure as an assault and battery which is legitimized only by the patient's express or implied consent. With specific reference to transplantation, he says "[I] would advocate viewing the whole transaction, from the start with the living donor to the finish .... as one composite curative transaction. Even where blood, kidneys or corneas are stored, their removal is not in the nature of assault and battery . .. but is to be considered part of an intricate, curative procedure." Daube, Transplantation: Acceptability of Procedures and the Required Legal Sanctions, in Erhics aND Madical Progress I88, I94 (G. Wolstenholme \& M. O'Connor eds. I966).

The perverseness of the law's assault and battery analogy is paralleled by that of the maxim quoted in the text, and one might hope that the implicit bias or burden of proof might be reversed by courts willing to recognize and endorse the experimental as well as the curative aspect of medicine. Still, this should not mean that the doctor should be permitted to balance the conflicting claims of science and the patient in a particular case but only that adherence to prevailing professional standards concerning informed consent and due care will relieve the doctor of liability.

12 See Ladimer, supra note 39 , at $476-80$.
} 
pertain to medical practice and medical licensure ought to recognize explicitly the investigative component of medical practice; advancing medical knowledge has, after all, been a part of the duty of the physician since the beginning of the scientific revolution.

\section{F. A Digression on Law and the Educative Aspect of Medicine}

Having referred to the law's seeming undervaluation of medicine's investigational responsibilities, we may appropriately digress from the subject of transplantation to note briefly some aspects of the law's attitude concerning the third component of the classic triad of medical care, the educative component.

The teaching of medicine has been regarded as an important activity within the profession since Hippocrates gave it prominence in the Oath of the Physician. Like research, teaching, unless too narrowly defined, is to some extent a part of virtually all types of medical practice. Only in the practice of solitary physicians in remote areas could one possibly find examples of medical practice almost totally devoid of both teaching and research. The training of new doctors and other medical personnel and the continuing education of practitioners is an essential element of providing medical services on a continuous basis, and there will necessarily be occasions when the best interests of individual patients may seem to be in conflict with educational goals. The law and the makers of policy must be alert to the importance of the educational function in resolving these apparent conflicts.

The law's undervaluation or misconception of the teaching element in the rendering of medical services is most apparent in Medicare regulations requiring that all surgical procedures on Medicare patients be performed by or under the "personal and identifiable direction of"-interpreted in the case of surgery as meaning "supervision in person by"-a staff surgeon other than an intern or resident. ${ }^{43}$ This requirement must be met if a "reasonable charge" is to be collected under the Medicare program for the professional services rendered. The alternative, if supervision is not provided, is to have only some small portion of the resident's salary and other costs associated with the surgery reimbursed to the hospital. ${ }^{44}$ The effect is thus to deny the usual professional fee on the ground that the surgeon, while professionally competent to perform the particular procedure, was still only a resident. The economic impact will be such that hospitals will in most cases provide the required supervision, at a loss of efficiency in the use of medical manpower and, as indicated below, of important educational advantages. In many instances, it can be predicted, the additional supervision provided will be only perfunctory because of the senior surgeon's feeling that his presence is not necessary except to qualify under these regulations.

\footnotetext{
${ }^{48}$ Social Security Administration Reg. $\$ 405.521$ (b), 32 Fed. Reg. 12,602 (1967).

${ }^{14}$ Social Security Administration Reg. $\$ 405.52 \mathrm{I}$ (d), 32 Fed. Reg. 12,602 (r967), quoted in note 46 infra. The principle seems to be that the hospital's economic costs are to be covered but nothing morc.
} 
The chief objection that has been raised to these regulations has been their failure to make allowance for the essential characteristics of surgical training whereby the young surgeon is gradually given greater and greater responsibility, performing procedures of increasing difficulty throughout his residency. ${ }^{45}$ By arbitrarily dividing surgeons into two groups, the trained and the untrained, without regard to the particular procedure and the individual's competence to perform it, the regulations misconceive and undercut the training process by penalizing the process of gradual exposure of the young doctor to responsibility in the operating room. ${ }^{46}$ Thus, the regulation accords the diagnostic and treatment aspect of medicine a place in policy formation without due regard for the educative aspect; surely the careful education and training of young surgeons should be given greater weight. The regulation's deficiencies may be seen as an attempt to secure for Medicare patients the services of fully trained surgeons, in reaction against the impression that public patients have in the past been made available to residents and interns for "practice." The assumption that care rendered by interns and residents is necessarily of less than the best quality is unwarranted. In properly conducted training programs the residents-trained in the particular procedures which they undertake, supervised and assisted by senior surgeons as needed, and backed by all of the hospital's resources-provide surgical care which is of the same quality as that rendered personally by senior surgeons. Training in even the most complex and difficult procedures can and should always be accomplished without sacrifice in the quality of the diagnostic and treatment services rendered to the patients involved. There can never be any justification for accepting the needs for education and training as an excuse for providing less than the best in this quality. Notions to the contrary are fostered in the minds of the public by present Medicare policy, to the detriment of training programs.

\footnotetext{
${ }^{45}$ See Russell, Surgical Education and Social Change, 62 SurgerY 56I (1967).

${ }^{40}$ Social Security Administration Reg. $\S 405.52 \mathrm{I}(d), 32$ Fed. Reg. I2,602 (1967), purports to recognize the educational considerations and indicates a belief that reimbursement of the resident's salary and other costs is sufficient compensation to the hospital:

"(d) It is recognized that there will necessarily be situations where a patient will receive medical services in the teaching setting for which payment on the basis of reasonable charges will not be applicable. For example, there will be instances where it will neither be necessary from the standpoint of the medical needs of the patient nor appropriate from the standpoint of the continuing development of the residents' competence for there to be an attending physician who carries out the responsibilities referred to in paragraph (b) of this section. Whether or not a physician makes a charge recognized under the supplementary medical insurance program for services to patients which involve the participation of residents or interns, the hopsital can receive reimbursement on a cost basis for an appropriate share of the compensation it pays its residents and interns. If the teaching program is an approved educational activity of the hospital, reimbursement will also be available on a cost basis to the hospital for an appropriate share of the compensation it pays to physicians for teaching services (as opposed to professional services which contribute to the diagnosis or treatment of the patient) and for other costs of educational programs conducted by the hospital. These costs are allowable in accordance with the principles of reimbursement for provider costs (see $\$ 405.42 I$ of Subpart D)."

The effect, nevertheless, is to deny recovery for the value of services rendered, and the economic impact, either of foregoing the fee or of providing the additional supervision, will be felt in the cost of the hospital's other services.
} 
Another area where social objectives, coupled with a faulty perspective on the needs of medical education, may tempt the law to intrude is the matter of patient privacy in teaching hospitals. Traditionally, public patients are exposed to residents, interns, medical students, other hospital personnel, and other patients more than are private patients; and public patients for understandable reasons are provided in many instances with less comfortable waiting, examining, and treating facilities. Private patients often are given priority over public patients in the scheduling of diagnostic and treatment procedures such as $\mathrm{x}$-rays and operations. ${ }^{47}$ It is thus understandable, and perhaps proper, that social progress would dictate some legal protection of Medicare clients and public patients from undue and demeaning intrusions on their personal privacy; but there persists a danger that the teaching process will be impaired if the patient population easily available for teaching purposes is curtailed or eliminated. Primary reliance for dealing with this problem must ultimately be placed on doctors' professional responsibility and on teaching hospitals' ability to instill proper attitudes. Legal and regulatory involvement in this area, if ultimately required as the result of the inadequacy of voluntary efforts, should be limited, it would seem, to the establishment of advisory guidelines created to balance the needs of medical education against patients' legitimate expectations concerning their personal dignity.

\section{G. Transplantation, Privacy, and the Free Press}

The patient and his family generally seek privacy especially when experiencing a crisis. There is hardly a time when they are less prepared to interview a reporter than when a transplant operation in the family is about to be performed or has just been performed. Both donor and recipient may be relatively young and parents of several dependent children; and the outcome, at least for the recipient, is all too uncertain. Despite carefully considered decisions beforehand, the tension within the family may be heightened by anxieties as to whether the right decisions were made. These feelings persist for days and subside only as evidence accumulates that all is going well. Public curiosity and the persistence of reporters are apt to appear morbid and to be resented. Exceptions to these observations do occur-most recently and most notably in the case of the South African who received the first heart transplantbut most families would prefer to avoid the notoriety.

Two separate factors can be identified in support of respecting the right of the patient and his relatives to privacy during such a crisis. One is the natural desire and simple right to be left alone. The other factor relates to the consent of the donor as discussed in a preceding section. There is general agreement that the freedom of the kidney donor to revoke his consent at any time, even at the last minute, must be protected. Revelation of the identity of the prospective kidney

\footnotetext{
${ }^{17}$ Davis, The Future of Medical Education and Its Relationship to the Teaching Hospital, 31 THE Pharos of Alpha OMEga Alpha 6 (1968).
} 
donor to a reporter, with or without a promise to withhold publication until after the transplant, would be inimical to this freedom. Families therefore ought to be counseled to avoid involvement with reporters especially prior to the operation. Overtures to "do a complete documentary" on a family experiencing a kidney transplant, beginning with pre-transplant interviews, ought to be discouraged in the strongest possible terms.

On the other hand the public news media have a responsibility in events which are of public interest. The level of interest tends to be high with regard to the introduction of new forms of treatment and with regard to procedures which capture the public imagination, such as transplantation of a vital organ from one person (living or dead) into another. Pursuit of stories and information which the public either needs or enjoys is a duty of the newsman. A number of effective techniques are available and necessary at times to obtain information which is either inherently difficult to obtain or deliberately repressed. How intensively, however, ought these efforts be pursued when invasion of privacy becomes a question?

In coping with situations wherein intense public interest tends to invade privacy, one needs a reasonable guide for determining which interest shall take precedence. Perhaps it would be useful to draw a distinction between two categories of public interest: public curiosity, which has little bearing on public welfare, and public concern, upon which public welfare does depend. To illustrate the distinction, the health of a particular private citizen may be the subject of intense public curiosity but not be of legitimate public concern; whereas the health of a candidate for public office is of legitimate concern to the voting public. The public needs to be kept informed with regard to newly available forms of treatment; and indeed, new forms of treatment do not reach their full potential of usefulness if the public is not informed. With few exceptions, however, the public does not need to know the personal details of individual patients undergoing new forms of treatment. Public curiosity, however intense, does not justify the revelation of personal details without the freely given consent of the persons involved.

The physician's first concern should of course be for his patient, so that when public curiosity threatens the patient's privacy and peace of mind he instinctively reacts protectively in behalf of the patient, who physically and emotionally may not be in a good position to protect himself. Of course the physician who is a clinical investigator has an additional responsibility, namely to publish the results of his studies. These he publishes in the scientific literature, thereby subjecting his findings to the critical review of the scientific community. Premature accounts in lay publications typically are overly enthusiastic about significance of success and discovery and, therefore, are more misleading than informational. As Moore $^{48}$ has emphasized, however, articles in the public news media are important sources of public education,

\footnotetext{
${ }^{48}$ F. Moore, Give and Take i69 (I964).
} 
and the professional scientist can enhance the value of such articles by providing background information to science writers. Because the educational value of such writings depends little if at all on the identity and personal circumstances of patients, exclusion of information which tends to invade privacy generally does not reduce the value of articles. Moreover, it is through the use of personal information that articles not infrequently are given an emotional pitch which misleads readers. As judged from misimpressions which readers receive as a result of emotional slant, they sometimes misinterpret factually accurate articles. Personal information, then, is nonessential to educational content and actually can be detrimental.

News writers and science writers take the position that inclusion of personal information is important on occasion to increase interest, to increase the number of readers, and therefore to increase the total educational effect of an article. No exception is taken to this position. The patient is free to release personal information if he wishes to, and in order to enhance readership and to satisfy public curiosity, the writer is free to use personal information with the consent of the patient. The only constraints suggested are (I) that personal information be obtained without pressure (which invalidates consent and which is itself an invasion) and at a time which is suitable to the patient; and (2) that, when used, personal information be used in a manner to enhance and not to detract from educational effect.

\section{Conctusion}

Transplantation of tissues and organs accounts for many of the medical-legal questions that have arisen during the last decade or two in the wake of rapid advances in medical science. ${ }^{49}$ In the foregoing discussion of some of these questions one can distinguish two means through which these questions can be approached and through which associated problems can be prevented or resolved.

First, there is the means of self-government and self-regulation within the medical profession. Numerous examples can be cited wherein general adherence to written or unwritten codes and standards of medical practice either have not left opportunity for problems to arise or have satisfactorily solved those problems that did arise. This approach, where applicable, has the great advantages of directness and simplicity. But to be applicable this approach must be effective and must be attuned to the expectations of the public.

Second, there is the means of answering questions and preventing or resolving medical-legal problems through the mechanisms of the courts, the legislatures, and the administrative offices having jurisdiction. Examples can be cited for which this is the only feasible approach. Perhaps the best current example of this approach is the drafting of the Uniform Anatomical Gift Act, a piece of recommended legis-

${ }^{\circ}$ Stickel, Ethical and Moral Aspects of Transplantation, 3 Monographs in the Surgical Sciences 267 (I966). 
lation which will bring together logically a complex of interrelated medical and legal considerations. This approach, too, must be responsive to the feelings and the needs of the public, and if it is to be effective in producing workable principles it must have the benefit of considerable joint medical and legal effort in the preparation and argument of cases, in the drafting of and lobbying for new legislation, and in the presentation of viewpoints and evidence to the responsible administrators. 